\title{
An investigation on nuclear energy policy in Turkey and public perception
}

\author{
Mehmet Burhanettin Coskun ${ }^{1}$, Banu Tanriover $^{2}$ \\ ${ }^{1}$ Department of Politics and Public Administration, Osmaniye Korkut Ata University, Osmaniye, Turkey \\ ${ }^{2}$ Department of Economics, Osmaniye Korkut Ata University, Osmaniye, Turkey
}

\begin{abstract}
Turkey, which meets nearly 70 per cent of its energy demands with import, is facing the problems of energy security and current account deficit as a result of its dependence on foreign sources in terms of energy input. It is also known that Turkey is having environmental problems due to the increases in $\mathrm{CO}_{2}$ emission. Considering these problems in Turkish economy, where energy input is commonly used, it is necessary to use energy sources efficiently and provide alternative energy sources. Due to the dependency of renewable sources on meteorological conditions (the absence of enough sun, wind, and water sources), the energy generation could not be provided efficiently and permanently from these sources. At this point, nuclear energy as an alternative energy source maintains its importance as a sustainable energy source that providing energy in 7 days and 24 hours. The main purpose of this study is to evaluate the nuclear energy subject within the context of negative public perceptions emerged after Chernobyl (1986) and Fukushima (2011) disasters and to investigate in the economic framework.
\end{abstract}

\section{Introduction}

Quest created by the growing need for sustainable energy in Turkey has started to highlight the various renewable energy needs. This creates the need for nuclear energy of the first actors to trigger the global and technological development as well as establishing and operating direction of the well has now started to be observed to make a functional form that can spread the form of energy production. Nuclear power plants and power centers of the energy system could be used in our country to build off of existing nuclear power plants is clear that the most rational approach is no longer a hidden fact. Brought to life within the context of this reality constitutes the main subject of the Energy Policy and Public Perception survey creation in Turkey.

As an alternative solution that can contribute to the current electricity generation of Turkey's energy needs, the basic aim of the research on nuclear energy in which there is a positive example on the world economic paradigm, social and political returns to be created in the public perception of environmentally compatible systems in nuclear power consumption reveal positive and negative and made public which is to contribute to the reduction of false cause of uncertain thoughts. With this conceptual idea of the benefits of nuclear power use is not only about the national doubts but also with their expectations and perceptions.
Globalization in the area where the production of energy spending and economic competition with countries has been diligently calculated deficits and dependencies. It is able to show growth without getting stuck on the negative perception of Turkey will provide the benefits of nuclear energy policy? In this research, descriptive and explanatory methods were used to put forward the findings identified in this line of thinking.

This paper is organized as follows. Section 2 gives an overview about the role and importance of nuclear power plants in the world. Section 3 presents the energy problematical and nuclear energy policies in Turkey. The public perception of nuclear energy in Turkey has been evaluated in the section 4. Conclusions and discussions have been given in the section 5 .

\section{The role and importance of nuclear power in the World}

After the first use of nuclear energy for electricity production in the US, it began to be used in electricity production by England in 1953, by Russia in 1954, by France 1956 and by Germany in 1961. 10 countries in the 1960 's and subsequently 10 countries more in 1970's began producing electricity based on nuclear technology. The oil crisis of the early 1970's has increased the demand 
for nuclear power plants and launched a wave of constructing these plants. Next decade slowdown in the global economy and the decline in fossil fuel prices has restricted the growth of nuclear energy demand. Contrary to this, serious concerns occurred about the safety of nuclear facilities on a number of public by the impact of nuclear power plant accidents. However, some countries have continued construction of the reactor, and this has resulted in a limited increase in nuclear energy [1].

When historical development of nuclear energy is examined; it can be seen that the first use in order to generate electricity in the past in a commercial nuclear power has been in 1954. Nuclear energy was considered to be the largest source of energy on the world as "cheap, clean and safe" after the transition term of oil. Although it is understood that the end of $20^{\text {th }}$ century it is not so easy accomplish it but, it is also an irresistible truth that many developed or developing countries is spreading increasingly to nuclear power plants. One of these countries is Turkey which is planning to get electrical energy from nuclear plants [2].

Currently $17 \%$ of the world's electricity needs are obtained by nuclear energy, nuclear technology industry and by the use of production of isotopes it is also an important issue for many other sectors such as in medicine except energy [3]. Nuclear power plants began to be built after the discovery of the energy obtained from the nucleus of nuclear weapons [4]. Nuclear power plants improved in this process due to Britain's, America's and Russia's studies by using it for military purposes in the early 1944's [5]. The first nuclear power plant to produce electricity in the world was founded in Russia in 1954. After Russia, economic giants such as the US, Britain and France built nuclear power plants [6].

Today, nuclear energy is getting widespread use in some parts of the world as a kind of energy. Almost $17 \%$ of the electricity need is supplied by nuclear energy with approximately 440 nuclear power plant worldwide. In some countries and regions, a large part of the energy requirements is supplied by the nuclear power [7].

Up to $87 \%$ of nuclear power generation is held by OECD countries worldwide [8]. The number of countries which use nuclear power is very limited. There are 31 countries (16\%) which have nuclear power in United Nations. The $3 / 4$ of the world's nuclear power is generated by US, France, Japan, Germany and South Korea. In addition to this, these countries have nuclear weapons [9] For example this ratio is $78 \%$ in France and $20 \%$ in US. The alternative energies weren't used such as wind and geothermal during rapid spread of nuclear energy. However, due to the increase in security measures today, nuclear waste and licensing costs, nuclear energy costs increased fairly [10].
On the other hand, Sweden which has 12 and Germany which has 21 nuclear power plants have stopped the new nuclear power plant projects. Both two countries will also close their nuclear power plants until 2020. Austria, Denmark, Italy and Spain, have no nuclear power plant project in their agenda [11] Indeed, Germany also began to criticize policies on nuclear countries such as Belgium to stop the activities of nuclear power plants and it became a very serious discussion.

Germany has requested the closure of two nuclear power plants of Belgium on the grounds of the threats. Electricity generation supplied from nuclear energy plants is ranging from $1.5 \%$ to $2.5 \%$ worldwide. In general, the world has witnessed a decline in the production capacity of nuclear power due to the responses from the public, the problems encountered in the storage of waste, concerns and proliferation of nuclear weapons and difficulties encountered in the nuclear energy industry [9].

\section{Energy problematical and nuclear energy policies in Turkey}

Energy, which is one of the main inputs of industrialisation process, is an important factor of production in order to ensure sustainable development. Approximately $75 \%$ of energy demand in the world is provided from fossil fuels. If new energy sources are not derived, it is estimated that fossil fuels will run out after about 70 years and the world's energy crisis will become. Fossil fuels are limited amount and also cause environmental problems due to the increases in $\mathrm{CO}_{2}$ emission. In the recent years, the strategy independency in energy, which is one of the objectives of national economy recently, dramatic increases in energy demands as a result of industrialisation and technological developments and the fact that energy sources are decreasing rapidly are to turn the countries to the quest for new energy. Turkey, which meets nearly 70 per cent of its energy demands with import, is facing the problems of energy security and current account deficit as a result of its dependence on foreign sources in terms of energy input. It is also known that Turkey is having environmental problems due to the increases in $\mathrm{CO}_{2}$ emission. Considering these problems in Turkish economy, where energy input is commonly used, it is necessary to use energy sources efficiently and provide alternative energy sources.

These alternative energy sources include in nuclear energy and renewable energy such as wind, wave, biomass, geothermal, hydraulic and hydrogen energy. Due to the dependency of renewable sources on meteorological conditions (the absence of enough sun, wind, and water sources), the energy generation could not be provided efficiently and 
permanently from these sources. At this point, nuclear energy as an alternative energy source maintains its importance as a sustainable energy source that providing energy in 7 days and 24 hours. Therefore, just in being the $21^{\text {st }}$ century, new energy generation projects that considered the global climate changes and sustainable development, have become important. Especially, oil crisis occurred in the beginning of 1970's accelerated these initiatives and provided to come to the forefront of nuclear energy as a reliable source. Consequently until the second half of the 1980's many nuclear reactors were installed and put into operation. However by the end of 1980's demand for nuclear energy decreased and during 1990's this demand became stable. Three Mile Island (1979, USA) and Chernobyl (1986, former USSR) nuclear accidents, the recession in the world economy, and penetration of natural gas to the energy generation market are shown among results [12]

It is also clear that almost all of the natural gas and liquid fuels and $30 \%$ of coal used for electricity generation in Turkey are imported from other countries. On the other hand, in case all of Turkey's renewable energy sources like hydroelectric, wind, solar, geothermal and biomass are used for generating electricity, the half of the Turkey's electricity consumption demand of 500 billion $\mathrm{kWh}$ could be provided from these sources alone. Therefore, the important of nuclear energy as an alternative energy source is increasing day by day to be reducing of dependence on foreign sources in energy, to be reducing of emissions in the result from using fossil fuels, to be increase the international competitive power, to offer alternative sources to transitory supply resulting from the use of renewable energy sources. The other reasons why nuclear energy is preferred world-wide and in Turkey for electricity generation are following [13]: -Nuclear power plants have the continuous availability in generating electricity. Otherwise, the generated electricity depends on the right meteorological conditions in renewable energy sources power plants and the quality and composition of coal in coal fired plants and the quantity of reserves in fuel and natural gas power plants. Nuclear power plants do not require specific locations in order to generate large amounts of power.

-While considering nuclear fuel cycle, nuclear power plants are the eco-friendly option for greenhouse gas emissions to the environment. There are no released gases while nuclear power plant operated just as in released by combustion of fossil fuels like carbon monoxide, carbon dioxide, sulphur dioxide and nitrogen oxides gases. Nuclear energy stations do not emit criteria pollutants or greenhouse gases when they generate electricity. Because of this, nuclear energy has an inevitable role in reducing the greenhouse gas emissions caused to the climate change. Nowadays, the emitted greenhouse gases amount is reduced approximately by $17 \%$ annually due to the electricity generated in nuclear power plants. If the fossil fuel power plants are used instead of nuclear power plants, the emitted carbon gas amount would be 1,2 billion tons.

Table 1. Changes in costs of unit electrical production when fuel prices and ratios doubled in operations

\begin{tabular}{ccc}
\hline Fuel Type & $\begin{array}{c}\text { Used Fuel } \\
\text { Ratio }\end{array}$ & $\begin{array}{c}\text { Changes in Costs } \\
\text { When Fuel Prices } \\
\text { Doubled }\end{array}$ \\
\hline Coal & $77 \%$ & $31 \%$ increase \\
Natural Gas & $90 \%$ & $66 \%$ increase \\
Nuclear & $30 \%$ & $9 \%$ increase \\
Energy & Resources & International (ERI), \\
\hline Source: Energy &
\end{tabular}

-As shown in Table 1, the share of nuclear fuel in operating cost is around $30 \%$ (while this is $77 \%$ for coal power plants and $90 \%$ for natural gas power plants). Directly, the fluctuations in nuclear fuel prices is less impressed the cost of electricity production in nuclear power plants. When the fuel prices doubled, the effect of that cost increase the total operating cost in $66 \%$ in natural gas and in 31 $\%$ in coal.

-Nuclear power plants contribute to country's economic development by providing new employment areas.

-The generated energy from nuclear power plants diversifies the energy resources portfolio of country.

\section{Public perception of nuclear energy in Turkey}

Increasing world population, natural resource consumption trends and developments and the need for industrial machinery is directly pushing forward the use of limited fossil fuels. It can be seen that renewable energy sources move in a linear relationship with the establishment of nuclear power plants. Now the developed world countries are making an effort to get ahead of coming to dangerous levels of greenhouse gas emissions. All member countries of the UN were encouraged to be won a strong action plan with a consensus and accordingly the use of technology to prevent the increase of fossil fuel use within a program in order to apply needs increasing gradually.

In December 2015, members of the United Nations countries had participation and prepared a preliminary protocol by consensus in Paris. After that on 22nd April 2016 unanimous vote of the 195 
representatives of UN countries accepted "climate change" with the signatures as a protocol in New York. The protocol seeks to reduce this global warming almost 2 degrees for next century and 100 billion US dollars budget allocation was decided for developing countries. Thus, emission attack against the car company that we see recently and against greenhouse gas emissions to be taken by the countries which took the lead may be in tightening measures and global warming may also be prevented.

At this point, while the global warming and greenhouse gas emissions were discussed, the issue remained almost alone on our fossil fuel dependence on energy imports and our review has required more serious public perception and people witness to the government policy to support efforts to strengthen the energy perception on this issue. We can observe that the nuclear issue is being mentioned by both by scientists and politicians in addition to appearance of the benefits and damages raised from the use of nuclear energy and to eliminate the negative perception to Turkey which was affected by the Chernobyl nuclear accident in 1986.

Despite the expansion of the technological and economical use of maturation, the perception of nuclear energy on people stands in a different place among other energy sources. Many factors has contributed to this idea such as military purposes, the possibility that can be used to make weapons, technical complexity, long-term effects of nuclear waste, complex insurance requirements and safety law, the results associated with potential accidents, many health effects and high initial investment costs of exposure to ionizing radiation. Nuclear energy can be better understood by the help of well assimilation of these issues [1].

It is scientifically proven today that nonrenewable energy sources such as oil, natural gas and coal is projected to be used respectively in 54year period, 64 years and 112 years and decreases day by day. While the amount of total energy production from fossil fuels in the world is 10,905.9 Mtoe, the consumption amount stood at 10,689 Mtoe [14]. This is where the nations' economic, social and in accordance with the nature of nuclear energy will occur as general acceptance of a result on a basic social perception. It is important that this perception to be presented in the form of campaigns with rational and analytical grounds.

\section{Conclusion}

Global warming, rising energy costs and economic external dependence have been very important topics day by day in the world. These discussions in many of the developing countries and supranational organizations continue to create different reflexes. The main aim of these reflexes is to make a cleaner and more liveable world. Now it became mandatory to get a rational solution on growing energy needs and rising industrialization levels. Turkey is a developing country which has a very large amount of import. Current energy problems can be solved by a perception which can be creates from the thoughts of seasonal efficiency of renewable energy and minimizing the security issues on infrastructure of nuclear power plants. So it will be easy to build up the efficient use of nuclear power plants planned in Turkey. By the help of good management on public perception which is created by the thoughts above important steps may occur on closure of energy deficit, economic benefits and more liveable nature. It should be expanded with the perception that can be handled as a rational way of eliminating the energy problem with a nuclear energy policy fulfilled by taking into people's political will. A national nuclear energy policy should be determined in the perspective of national and international developments as healthy and correctly and adopted a multi-dimensional nature and the technical management of the use of nuclear energy in accordance with the requirements. In addition to this, sample strategies must be arranged to make this policy happen. As a result, for the success of a strong nuclear energy program with the creation of a political and scientific infrastructure there should be a conscious and sincere commitment.

\section{References}

1. TAEA, Turkish Atomic Energy Authority Energy Report, (2010).

2. TUYAP, The Energy Sector in Turkey, Evgin Stock Shares Research Press, 1, Istanbul, February, (1998).

3. U. Gursoy, The Social Costs and Clean and Renewable Sources of Energy, Turkish Medical Association Publications, (2004).

4. R. Karluk, Structural Transformation of Turkish Economy from 1923, Beta Press, (2007).

5. A. Satman, Symposium of Energy and Development in Turkey: Energy Sources in the World, Tasam Press, (2006).

6. TUBITAK, Vision 2023 The Project of Technological Foresight, Panel of Energy and Natural Sources, (2003).

7. M. Parfit, Alternative Energy, National Geographic, August 2005, pp. 76-106, (2005).

8. S. Kocak and H. Altun, Our Energy Needs and Nuclear Energy, Symposium of New and Renewable Energy Sources, TMMOB, 3-4 October 2003, pp. 397-400, Kayseri, (2003).

9. M. Schneider and A. Froggatt, The World Nuclear Industry Status Report, Brussels, (2004).

10. Y. Cengel, The Use of Geothermal, Wind and Other Renewable Energies in the World and 
Turkey", Symposium of New and Renewable Energy Sources, TMMOB, 3-4 October 2003, Kayseri, pp. 1-14, (2003).

11. E. Torunoglu, Is it Ecological Disaster Threshold: and the World is Polluted, Oteki Press, pp. 19-34. (1997).

12. Republic of Turkey Ministry of Energy and Natural Resources, Nuclear Energy Project Implementation Department Report, (2013).

13. V.S Ediger, Energy The New World Order, Turkish Sciences Academy, Academic Forum, No: 67, (2011).

14. BP, Statistical Review of World Energy, British Petroleum (BP), London, UK, (2012). 